\title{
Monosodium Glutamate as Selective Lixiviant for Alkaline Leaching of Zinc and Copper from Electric Arc Furnace Dust
}

\author{
Erik Prasetyo ${ }^{1, *}$, Corby Anderson ${ }^{2}$, Fajar Nurjaman ${ }^{1}$, Muhammad Al Muttaqii ${ }^{1}$, \\ Anton Sapto Handoko ${ }^{1}$, Fathan Bahfie ${ }^{1}$ (I) and Fika Rofiek Mufakhir ${ }^{1}$ \\ 1 Research Unit for Mineral Technology, Indonesian Institute of Sciences, Jl. Ir. Sutami km. 15 Tanjung \\ Bintang, Lampung Selatan 35361, Indonesia; nurjaman_80@yahoo.com (F.N.); \\ almuttaqiimuhammad@gmail.com (M.A.M.); e_electrical@yahoo.com (A.S.H.); \\ fathanbahfie@gmail.com (F.B.); fika.cupiw@gmail.com (F.R.M.) \\ 2 George Ansell Department of Metallurgical and Materials Engineering, Kroll Institute for Extractive \\ Metallurgy, Mining Engineering Department, Colorado School of Mines, 1500 Illinois St, Golden, CO 80401, \\ USA; cganders@mines.edu \\ * Correspondence: erik.prasetyo@lipi.go.id; Tel.: +62-721-350-054
}

Received: 27 April 2020; Accepted: 12 May 2020; Published: 15 May 2020

\begin{abstract}
The efficacy of monosodium glutamate (MSG) as a lixiviant for the selective and sustainable leaching of zinc and copper from electric arc furnace dust was tested. Batch leaching studies and XRD, XRF and SEM-EDS characterization confirmed the high leaching efficiency of zinc (reaching 99\%) and copper (reaching $86 \%$ ) leaving behind $\mathrm{Fe}, \mathrm{Al}, \mathrm{Ca}$ and $\mathrm{Mg}$ in the leaching residue. The separation factor (concentration ratio in pregnant leach solution) between zinc vs. other elements, and copper vs. other elements in the optimum condition could reach 11,700 and 250 times, respectively. The optimum conditions for the leaching scheme were $\mathrm{pH} 9$, MSG concentration $1 \mathrm{M}$ and pulp density $50 \mathrm{~g} / \mathrm{L}$. Kinetic studies (leaching time and temperature) revealed that the saturation value of leaching efficiency was attained within $2 \mathrm{~h}$ for zinc and $4 \mathrm{~h}$ for copper. Modeling of the kinetic experimental data indicated that the role of temperature on the leaching process was minor. The study also demonstrated the possibility of MSG recycling from pregnant leach solutions by precipitation as glutamic acid (>90\% recovery).
\end{abstract}

Keywords: electric arc furnace dust; monosodium glutamate; leaching; zinc; copper

\section{Introduction}

The demand for base metals such as zinc $(\mathrm{Zn})$ and copper $(\mathrm{Cu})$ has increased in recent years. Natural (primary) resources of both metals are dominated by sulfide ores, which unfortunately have declined both in quantity and grade causing discrepancies between supply and demand [1]. This in turn encourages the exploration of new resources, which not only includes primary resources but also secondary ones through recycling. Aside from helping address the resource depletion problem, the exploitation of secondary resources also mitigates environmental and resource sustainability problems. One of the secondary resources of base metal, which holds potential for further processing, is electric arc furnace (EAF) dust. The dust is a waste of steel making and is classified as hazardous [2]. The amount of dust produced during steel making is significant, where $11-20 \mathrm{~kg}$ of dust is generated for each ton of steel produced [3].

In addition to exploring new resources, extraction is also progressing toward green technology, which prioritizes the principles of efficiency, sustainability, safety and environmental impact. The EAF dust not only contains $\mathrm{Zn}$ and $\mathrm{Cu}$ as target elements but also others, e.g., lead $(\mathrm{Pb})$, chromium $(\mathrm{Cr})$, 
iron $(\mathrm{Fe})$, aluminum $(\mathrm{Al})$, calcium $(\mathrm{Ca})$ and magnesium $(\mathrm{Mg})$. $\mathrm{As} \mathrm{Pb}$ and $\mathrm{Cr}(\mathrm{VI})$ represent pollutants, their release into the environment during the extraction of $\mathrm{Zn}$ and $\mathrm{Cu}$ must be minimized and as such, a comprehensive study is required to formulate applicable technology to maximize benefits from EAF dust and minimize the impact of pollutants (heavy metals) to the environment.

One of the most widely applied methods to recover $\mathrm{Zn}$ and $\mathrm{Cu}$ from EAF dust is hydrometallurgy, especially in the case where $\mathrm{Zn}$ in EAF dust exists as zinc oxide. Other common $\mathrm{Zn}$ phases, i.e., zinc ferrite requires pre-treatment (e.g. fusion) [4,5]. The hydrometallurgical approach for $\mathrm{Zn}$ and $\mathrm{Cu}$ recovery involves a leaching process using chemical lixiviants to dissolve these metals in aqueous solution. Dissolved $\mathrm{Zn}$ and $\mathrm{Cu}$ in the pregnant leach solution can then be further separated and purified using solvent extraction [6,7], ion exchange [8] or electrochemical methods $[9,10]$. Several leaching schemes that use various lixiviants have been previously proposed in order to recover $\mathrm{Zn}$ and/or $\mathrm{Cu}$ from EAF dust at ambient and elevated temperatures, respectively. Halli et al., 2017 [11] had screened potential lixiviants including nitric acid, citric acid, sodium hydroxide and ethanol for metal recovery from EAF dust. Proposed lixiviants by other researchers include sulfuric acid [12-14], hydrochloric acid [15], oxalic acid [16], citric acid [17], sodium hydroxide [18-20], sodium carbonate/sodium bicarbonate [21], ammonia [22], imminodiacetic acid (IDA) [23] and nitrilotriacetic acid (NTA) [24].

In general, the leaching schemes proposed in the literature can be classified into four categories:

1. Acidic leaching using strong acid, e.g., sulfuric acid, hydrochloric acid.

2. Acidic leaching using organic lixiviants, e.g., oxalic acid, citric acid.

3. Alkaline leaching using bases, e.g., sodium hydroxide, sodium carbonate.

4. Alkaline leaching using organic lixiviants, e.g., nitrilotriacetic acid (NTA).

The first and second schemes are advantageous in terms of recovery efficiency but both lack selectivity. Other elements, especially Fe and Ca which would cause fouling in further separation and purification steps, and $\mathrm{Pb}$ or $\mathrm{Cr}$ which are toxic, are also extracted [25]. The third scheme possesses an advantage in terms of selectivity but the extraction efficiency is low, requiring very low pulp density ratio, high lixiviant concentration and high leaching temperature to attain satisfying recovery. In addition, the caustic and corrosive nature of lixiviant requires special handling and equipment during operation and also poses a risk to the environment. The same is true of schemes using strong acid as lixiviant to certain extent, especially leaching using high concentration (concentrated) mineral acid, e.g., Halli et al., 2017 [11].

Considering these factors, the fourth scheme presented is preferable, due to its relatively selective recovery of $\mathrm{Zn}$ and $\mathrm{Cu}$, higher leaching efficiency, safer handling in general compared to lixiviants in the other schemes and possibility to recover the lixiviant such as NTA. Although the leaching of base metal in this scheme is considered as selective, previous studies by Yang et al. (2016) [24] revealed relatively high extraction of iron, while the recovery of other elements such as $\mathrm{Ca}, \mathrm{Mg}$ and $\mathrm{Al}$ during leaching was yet to be addressed, where these elements play an important role in further separation and purification steps. The lixiviants in the fourth category rely on their ability to form complexes with metal ions. Aminocarboxylic acid ligands, e.g., IDA, NTA or ethylenediaminetetraacetic acid (EDTA) possess relatively strong yet homogenous binding capacity to the metal ions, not only target elements such as $\mathrm{Cu}$ and $\mathrm{Zn}$, but also matrix elements i.e. $\mathrm{Fe}, \mathrm{Al}, \mathrm{Mg}$ and $\mathrm{Ca}$.

In order to partition the matrix elements into the solid phase and the valuable elements into the aqueous phase, it is suggested to use a ligand which complexes preferentially to $\mathrm{Cu}$ and $\mathrm{Zn}$ and shows weaker affinity to $\mathrm{Ca}, \mathrm{Mg}$, Fe and $\mathrm{Al}$. Lixiviants such as amino acids broadly meet these criteria. Glycine has been extensively studied in copper [26] and gold [27] alkaline leaching, but to the best of our knowledge, no study on the efficacy of amino acid on Zn recovery has been carried out so far. Aside from glycine, another amino acid with potential to be developed as lixiviant is glutamic acid. In this research an amino acid sodium salt, i.e., monosodium glutamate (MSG) is proposed as a novel lixiviant. The advantages of MSG as a lixiviant include its wide availability and low price, and low risk to environment (biodegradable). MSG in alkaline conditions could serve as a powerful ligand to 
bind several transition metals, e.g., $\mathrm{Cu}$, which in turn increase the extraction efficiency. The complex formation of these metals with MSG have been reported and exploited in chemical analysis [28,29] and our preliminary research also confirmed its efficacy to extract Zn [30]. Another advantage of using MSG is its reusability, since MSG can be recovered from the pregnant leach solution as glutamic acid precipitate by acidification of pregnant leach solution (PLS). Considering these possible advantages of using MSG, a study to confirm its efficacy in $\mathrm{Zn}$ and $\mathrm{Cu}$ extraction from EAF dust is warranted. The effect of leaching parameters on the leaching efficiency such as $\mathrm{pH}$, lixiviant concentration, pulp density and kinetics, including selectivity toward other elements are investigated herein.

\section{Species Distribution Modeling for Leaching Efficiency and Selectivity Prediction}

The leaching efficiency and selectivity are hypothetically controlled by the distribution of species in the aqueous phase. Factors controlling this distribution include $\mathrm{pH}$ and concentration of metal ions and ligands/lixiviants involved in the system. The effect of $\mathrm{pH}$ on the recovery and selectivity could be predicted using a species distribution diagram, which was constructed using Visual MINTEQ 3.1 (KTH Royal Institute of Technology, Sweden). [31]. Figure 1 shows the species distribution of Zn and $\mathrm{Cu}$ in glutamate- $\mathrm{H}_{2} \mathrm{O}$ system as a function of $\mathrm{pH}$.

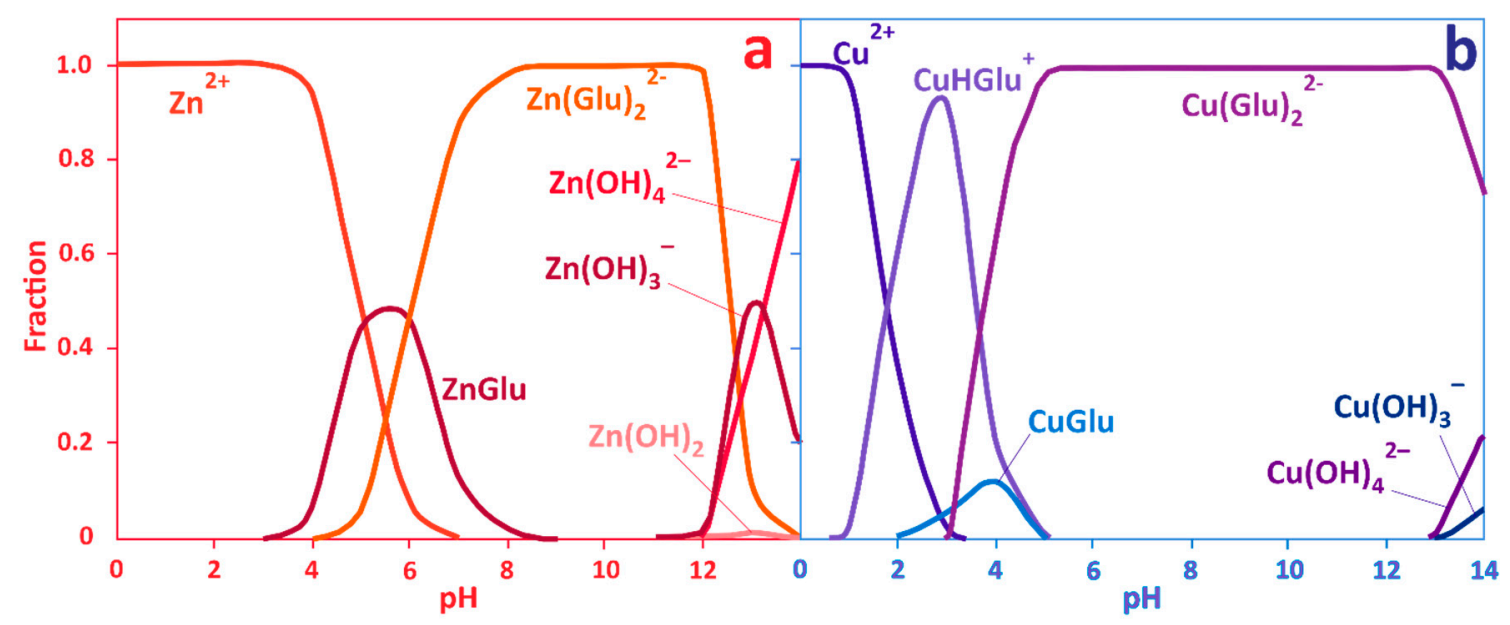

Figure 1. Species distribution of $\mathrm{Zn}(\mathbf{a})$ and $\mathrm{Cu}(\mathbf{b})$ in glutamate- $\mathrm{H} 2 \mathrm{O}$ system as function of $\mathrm{pH}$. Glutamate concentration $1 \mathrm{M}, \mathrm{Zn}^{2+} 300 \mathrm{mM}$ and $\mathrm{Cu}^{2+} 8 \mathrm{mM}$.

Based on Figure 1, in acidic conditions the species are dominated by free $\mathrm{Zn}^{2+}$ and $\mathrm{Cu}^{2+}$ ions. Glutamate as chelate effectively binds $\mathrm{Zn}$ and $\mathrm{Cu}$ from weakly acidic to alkaline conditions, and prevents the precipitation of hydroxides at strong alkaline $\mathrm{pH}$. The figure also shows that $\mathrm{Zn}$ starts to hydrolyze at $\mathrm{pH} 12$, while $\mathrm{Cu}$ at $\mathrm{pH} 13$. The program was also used to model the species distribution according to $\mathrm{pH}$ for other elements (Supplementary file: Figure S1), i.e., $\mathrm{Fe}, \mathrm{Mg}$, $\mathrm{Ca}$ and $\mathrm{Al}$. In general $\mathrm{Fe}$ and $\mathrm{Al}$ start to hydrolyze at weakly acidic $\mathrm{pH}( \pm 4)$, while $\mathrm{Mg}$ and $\mathrm{Ca}$ tend to hydrolyze at medium alkaline conditions ( $\mathrm{pH} 12)$.

Aside from species distribution, leaching selectivity can be predicted using the complex formation constant $\left(K_{f}\right)$ (Table 1). The constant was calculated for each complex, which might exist in the solution phase. Table 1 also lists the formation constants of metal ions with EDTA, NTA and glycinate as comparisons to assess the selectivity of organic compounds as lixiviants. If a lixiviant is expected to selectively bind one metal ion $(\alpha)$ and not another metal ion ( $\beta$ ), then the value of $K_{f \alpha} / K_{f \beta}$ has to be higher than $10^{6}\left(\log K_{f \alpha}-\log K_{f \beta} \geq 6\right)$ [32]. The value of complex formation constants for glutamate, which were calculated based on the model generated by Visual Minteq in Table 1, indicates the possibility of separation of $\mathrm{Zn}$ and $\mathrm{Cu}$ from $\mathrm{Mg}$ and $\mathrm{Ca}$, and also $\mathrm{Zn}$ from $\mathrm{Cu}$ using glutamate, and demonstrates better selectivity over the other chelators such as EDTA, NTA and glycine (amino acid). 
The weaker complex formation constants for Fe-glutamate compared to Fe-EDTA and Fe-NTA indicate the possibility of separation of $\mathrm{Zn}$ and $\mathrm{Cu}$ from Fe through Fe hydrolysis in alkaline condition.

Table 1. Log complex formation constant of metal ions with three organic compounds as chelator/lixiviants.

\begin{tabular}{ccccc}
\hline Ions & $\log K_{f}$ EDTA [33] & $\log K_{f}$ NTA [34] & $\log K_{f}$ Glycinate [35] & $\log K_{f}$ Glutamate (This Study) \\
\hline $\mathrm{Zn}^{2+}$ & 16.4 & 10.7 & 5.5 & 8.9 \\
\hline $\mathrm{Cu}^{2+}$ & 18.4 & 12.7 & 8.3 & 14.9 \\
\hline $\mathrm{Fe}^{3+}$ & 24.2 & 24.3 & 10.3 & 11.8 \\
\hline $\mathrm{Mg}^{2+}$ & 8.7 & 8.2 & 3.5 & 1.8 \\
\hline $\mathrm{Ca}^{2+}$ & 10.6 & 7.0 & 1.4 & 1.1 \\
\hline
\end{tabular}

\section{Experimental}

\subsection{Materials and Instrumentation}

EAF dust samples were kindly supplied by local smelters around Jakarta and Banten Province, Indonesia. A sieving test showed that more than $90 \%$ of dust passed through a 270 mesh $(53 \mu \mathrm{m})$, and this size fraction was used in further leaching tests. All leaching experiment and characterization studies were performed in the Research Unit for Mineral Technology-Indonesian Institute of Sciences, Bandar Lampung, Indonesia, or otherwise stated.

XRF characterization (Panalytical X'Pert 3 Powder with Omnian Standard) was carried out to determine the major chemical components in EAF dust (Table 2), and shows the most dominant constituents to be zinc and aluminum. The mineralogical phases were determined using X-ray powder diffraction (Panalytical, Expert3 Powder). Quantitative determination of metal contents in EAF dust (Table 3) and pregnant leach solution after leaching for recovery and separation factor calculation were carried out using atomic absorption spectrophotometry (AAS, Shimadzu AA7000, Japan) and Inductively Coupled Plasma-Optical Emission Spectrometry (ICP-OES, Analytik Jena, Plasma Quant 9000 Elite, Germany). SEM-EDS characterization to investigate the change of morphology and elemental distribution on the surface of EAF dust grain before and after leaching was performed using a SEM (Hitachi SUM 3500, Japan) at the Research Unit for Natural Product Technology-Indonesian Institute of Sciences, Yogyakarta, Indonesia. The advanced mineral identification and characterization system (AMICS) analysis to determine and map the mineral phases was carried out by Eagle Engineering, Butte, Montana, USA.

Chemicals such as sodium hydroxide, sulfuric acid, nitric acid, hydrochloric acid, and standard solutions were obtained from Merck, Darmstadt all in analytical grade, while monosodium glutamate was produced by PT Ajinomoto Indonesia (99\% purity) and used as received. The solution pH was adjusted using dilute sulfuric acid or sodium hydroxide and monitored using a pH meter (Oakton 45, Vernon Hills, IL, USA), while deionized water (MilliQ) was used throughout the experiment.

Table 2. Major chemical composition of electric arc furnace (EAF) dust.

\begin{tabular}{cccccccccccccc}
\hline Component & $\mathrm{MgO}$ & $\mathrm{Al}_{2} \mathrm{O}_{3}$ & $\mathrm{SiO}_{2}$ & $\mathrm{SO}_{3}$ & $\mathrm{~K}_{2} \mathrm{O}$ & $\mathrm{CaO}$ & $\mathrm{TiO}_{2}$ & $\mathrm{MnO}$ & $\mathrm{Fe}_{2} \mathrm{O}_{3}$ & $\mathrm{NiO}$ & $\mathrm{CuO}$ & $\mathrm{ZnO}$ & Total \\
\hline wt. $\%$ & 0.59 & 36.0 & 2.22 & 0.34 & 0.12 & 2.23 & 0.18 & 0.87 & 2.72 & 0.60 & 1.29 & 51.8 & 99.2 \\
\hline
\end{tabular}

Table 3. Chemical composition of important base metals in EAF dust (after aqua regia digestion and AAS/ICP-OES determination).

\begin{tabular}{ccccccc}
\hline Element & $\mathbf{C r}$ & $\mathbf{C u}$ & $\mathbf{F e}$ & $\mathbf{N i}$ & $\mathbf{P b}$ & $\mathbf{Z n}$ \\
\hline wt. $\%$ & $0.016 \pm 0.002$ & $0.898 \pm 0.021$ & $1.432 \pm 0.029$ & $0.522 \pm 0.008$ & $0.075 \pm 0.016$ & $38.652 \pm 0.428$ \\
\hline
\end{tabular}




\subsection{Leaching Procedure}

Leaching studies were carried out using a batch method. In general, $1 \mathrm{~g}$ of EAF dust was mixed with $20 \mathrm{~mL}$ lixiviant in $250 \mathrm{~mL}$ sealed flask. The mixture was homogenized using an orbital shaker at $200 \mathrm{rpm}$. After the leaching was completed, the supernatant solution was separated using centrifugation and filtration (Whatman 42). The metal concentration was determined using AAS or ICP-OES. Metal recovery $(R)$ was calculated using Equation (1). To evaluate the selectivity of the leaching scheme, a separation factor (SF) between $\mathrm{Zn}$ or $\mathrm{Cu}$ and other metals was evaluated using Equation (2). All leaching data were obtained in duplicates.

$$
R=\frac{C_{E} \times V}{C_{o} \times m} \times 100 \%
$$

where:

$C_{E} \mathrm{Zn}$ or $\mathrm{Cu}$ concentration in supernatant solution $(\mathrm{mg} / \mathrm{L})$

$C_{o} \mathrm{Zn}$ or $\mathrm{Cu}$ content in EAF dust $(\mathrm{mg} / \mathrm{g})$

$m$ mass of EAF dust used in leaching $(\mathrm{g})$

$V$ leaching agent volume (L)

$$
S F=\frac{C_{Z}}{C_{M}}
$$

where:

$C_{Z}, \mathrm{Zn}$ or $\mathrm{Cu}$ concentration in pregnant leach solution $(\mathrm{mg} / \mathrm{L})$.

$C_{M}$, other metal concentration in pregnant leach solution $(\mathrm{mg} / \mathrm{L})$.

\section{Results and Discussion}

\subsection{Characterization}

EAF dust characterization using XRD showed the mineral phase composition was dominated by zinc oxide ( $\mathrm{ZnO})$. XRD of the dust residue obtained after leaching (leaching condition $\mathrm{pH} 9$, MSG concentration $1 \mathrm{M}$, pulp density $50 \mathrm{~g} / \mathrm{L}$ and 12-hour homogenization) revealed the phases were dominated by spinel (Mg-Al oxide), calcium aluminum oxide and zinc oxide phases (Figure 2). These elements such as $\mathrm{Al}, \mathrm{Mg}, \mathrm{Ca}$ and Fe were found to be relatively retained in the solid phase during the leaching process. The XRD characterization results are supported by AMICS analysis results (Supplementary file: Tables S1 and S2 and Figure S2), which revealed the major Zn phase to be ZnO and gahnite $\left(\mathrm{ZnAl}_{2} \mathrm{O}_{4}\right)$ in original material. 

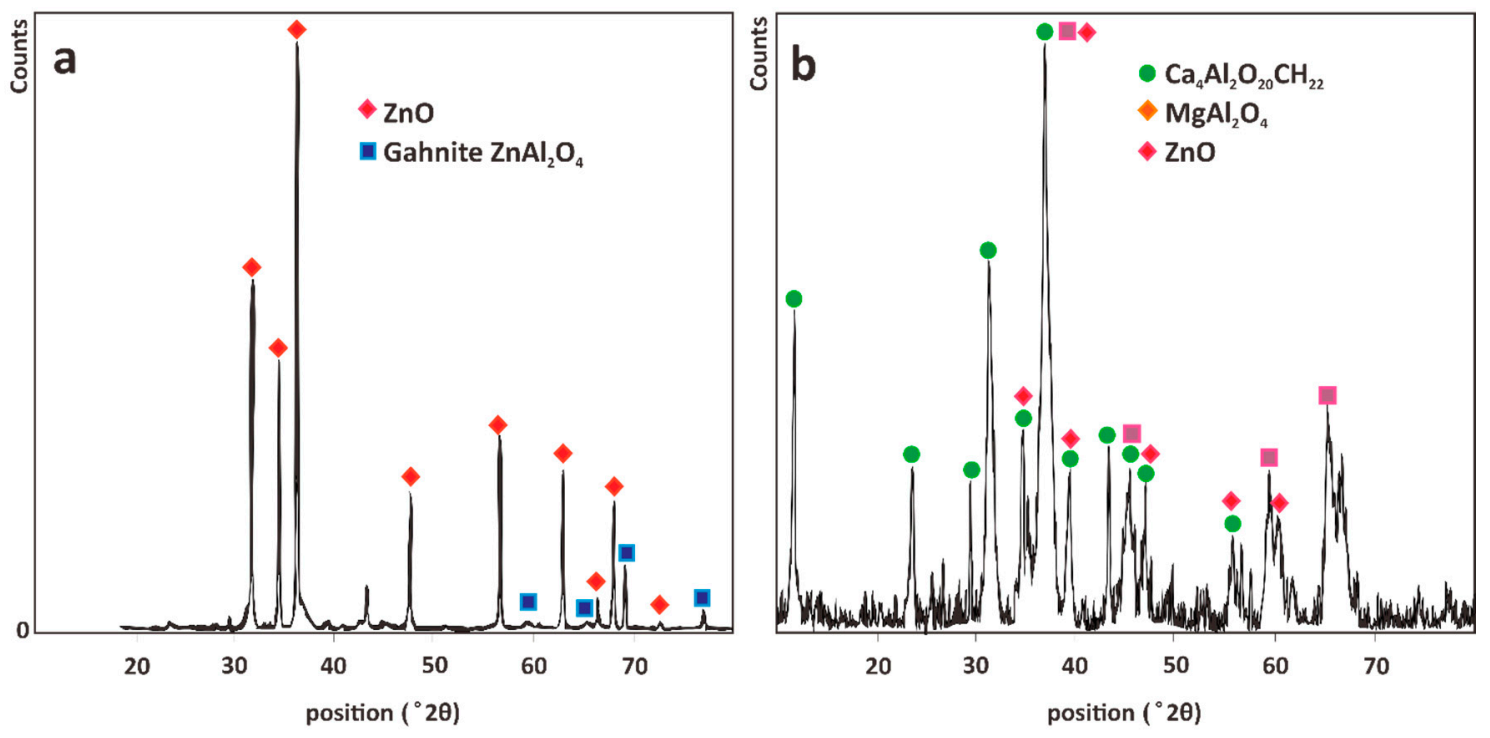

Figure 2. Phases present in EAF dust (a) before and (b) after leaching.

The change in elemental distribution of EAF dust before and after leaching was also explored by SEM-EDS characterization (Figure 3). Surface morphology of EAF dust changed from porous and grainy to relatively smooth. Intensity decrease of $\mathrm{Zn}$ and $\mathrm{Cu}$ peaks on the EDS profile after leaching confirmed the efficacy of MSG as lixiviant in EAF dust leaching. Qualitative mapping on the surface reveals that elements such as $\mathrm{Al}, \mathrm{Fe}$ and $\mathrm{Ca}$ were relatively retained and even enriched after leaching (Table 4), indicating the selective nature of the leaching using MSG.
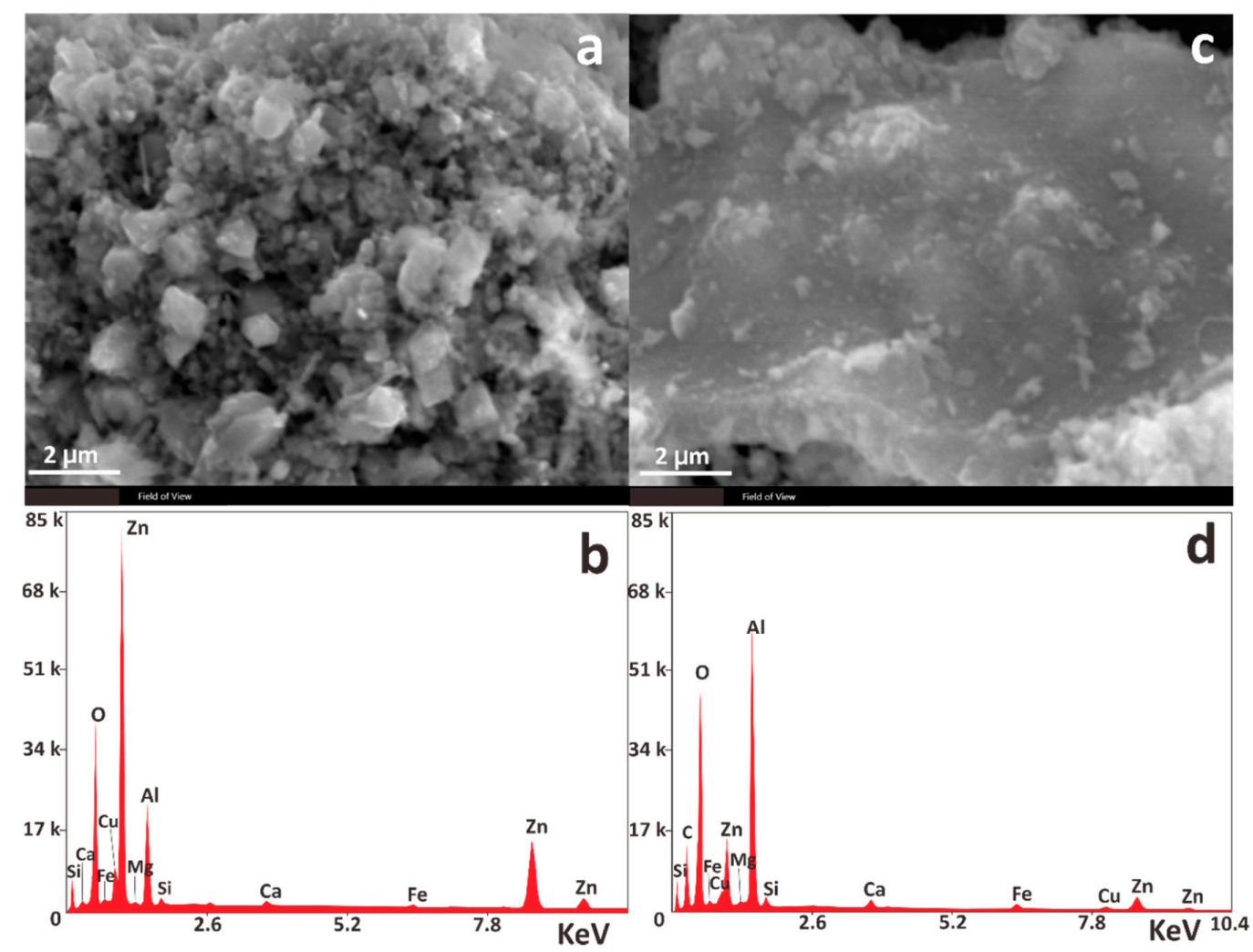

Figure 3. Morphology (a) before and (b) after leaching, including EDS intensities of elements based on mapping on the respective field (c) before and (d) after leaching. 
Table 4. Qualitative mapping of elements by EDS on grain surface before and after leaching.

\begin{tabular}{cccccccc}
\hline Elements & O K & Mg K & Al K & Si K & Ca K & Fe K & Zn K \\
\hline Before leaching $(w t \%)$ & 24.08 & 1.62 & 15.19 & 1.06 & 0.57 & 0.37 & 56.95 \\
\hline After leaching $(w t \%)$ & 35.53 & 0.57 & 20.42 & 0.90 & 1.00 & 1.30 & 6.99 \\
\hline
\end{tabular}

\subsection{Effect of $p H$}

The effect of $\mathrm{pH}$ on the $\mathrm{Zn}$ and $\mathrm{Cu}$ leaching efficiency and selective recovery was studied between 6 and 11 . The constant variables included MSG concentration $1 \mathrm{M}$, pulp density $50 \mathrm{~g} / \mathrm{L}$ and an agitation time of $12 \mathrm{~h}$ at room temperature. $\mathrm{pH}$ ranges between 6-11 were chosen according to the modeling in Section 2 in order to suppress the solubility of other elements $(\mathrm{Mg}, \mathrm{Ca}, \mathrm{Al}$ and $\mathrm{Fe})$. The leaching efficiency and leaching selectivity are shown in Figures 4 and 5, respectively.

Based on Figure 4, the optimum $\mathrm{pH}$ to recover $\mathrm{Zn}$ and $\mathrm{Cu}$ are 9. Low recovery at lower $\mathrm{pH}$ was due to the weaker or repulsive interaction between glutamate and $\mathrm{Zn}$ or $\mathrm{Cu}$ since the glutamate species was dominated as a protonated species, e.g., $\mathrm{H}_{3} \mathrm{Glu}^{+}, \mathrm{HGlu}^{-}$. Lower recovery at $\mathrm{pH}$ higher than 9 was probably due to the hydrolysis of $\mathrm{Zn}$ and $\mathrm{Cu}$, which was lower compared to the modeling results using Visual Minteq ( $\mathrm{pH}>12$ for $\mathrm{Zn}$ and $\mathrm{pH}>13$ for $\mathrm{Cu}$ ). In the case of other elements, all but $\mathrm{Al}$ extraction decreased as $\mathrm{pH}$ became alkaline. Increasing recovery of $\mathrm{Al}$ in alkaline conditions $(0.5 \%$ at $\mathrm{pH} 11)$ was due to the amphoteric characteristic of $\mathrm{Al}$, which is soluble in excess of alkali as $\mathrm{Al}(\mathrm{OH})_{4}{ }^{-}$.

Increasing $\mathrm{Al}$ recovery at higher $\mathrm{pH}$ and decreasing $\mathrm{Zn}$ or $\mathrm{Cu}$ contributed to the sharp decrease of the selectivity factor of $\mathrm{Zn}$ or $\mathrm{Cu}$ toward $\mathrm{Al}$ (Figure 5). The figure also shows the optimum $\mathrm{pH}$ to separate $\mathrm{Zn}$ and $\mathrm{Cu}$ are 9 and 10, respectively. The highest separation factor is obtained toward iron, which could reach an order of $10^{4}$ (with $\mathrm{Zn}$ ) and 400 (with $\mathrm{Cu}$ ). Lower separation factors were obtained between $\mathrm{Zn}$ or $\mathrm{Cu}$ and $\mathrm{Mg}$ and $\mathrm{Ca}$ (reaching an order of 700).
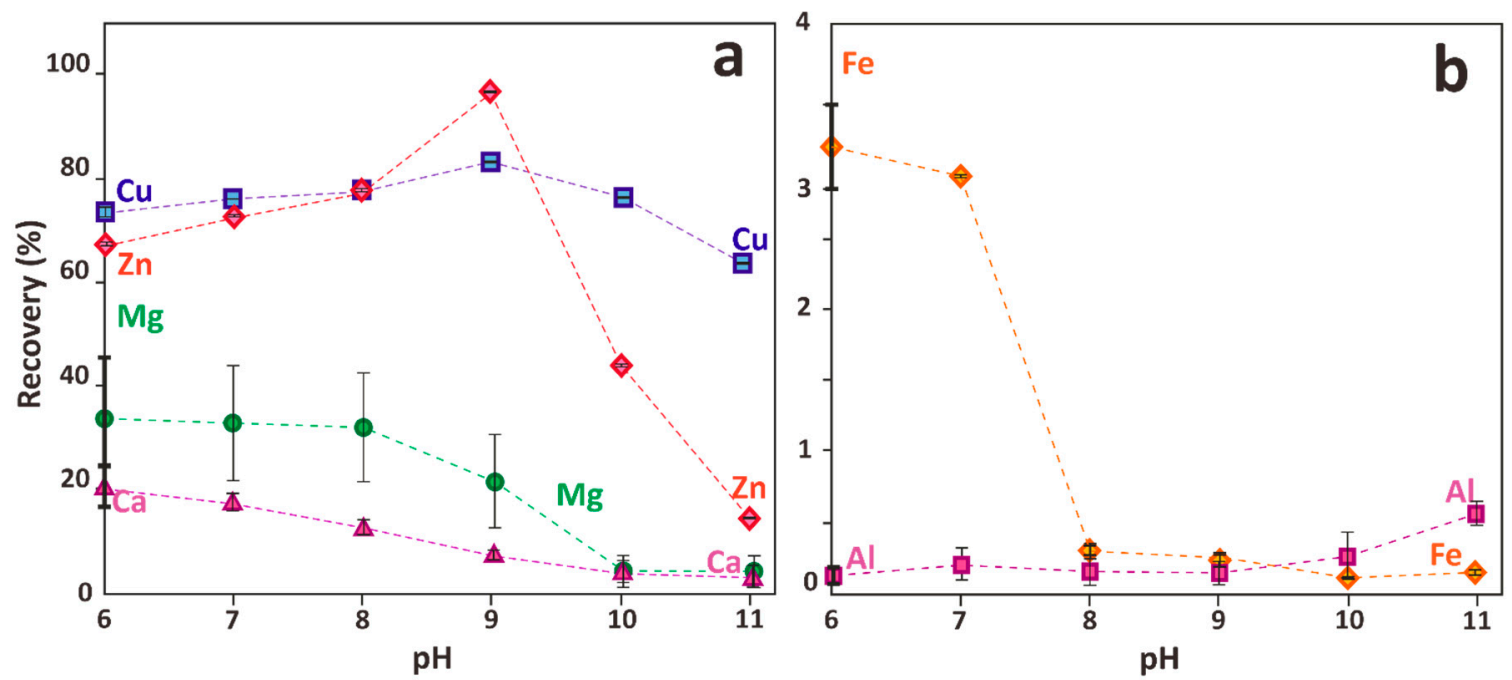

Figure 4. The recovery of (a) $\mathrm{Zn}, \mathrm{Cu}, \mathrm{Mg}$ and $\mathrm{Ca}$ and (b) Fe and $\mathrm{Al}$ as function of $\mathrm{pH}$. 


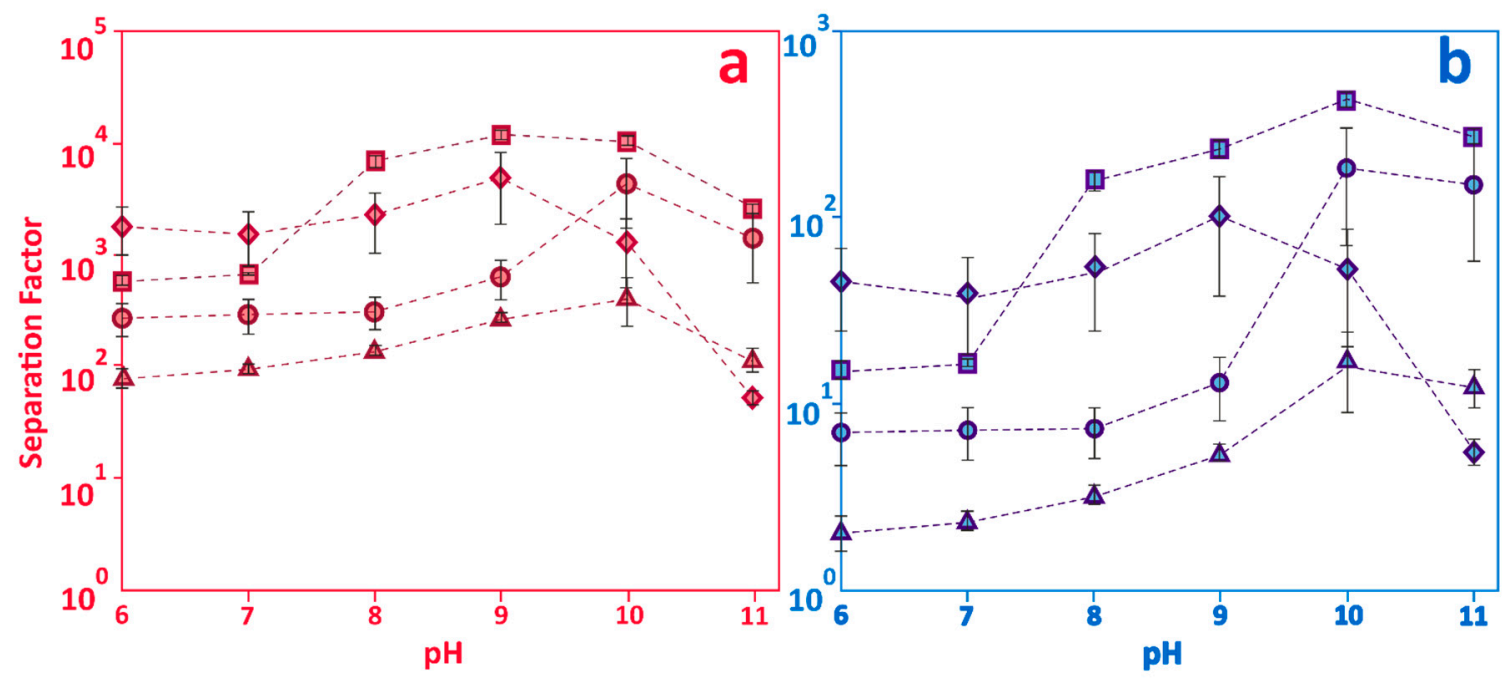

Figure 5. Separation factor of (a) Zn: [Zn]/[Fe] (squares), [Zn]/[Al] (diamonds), [Zn]/[Mg] (circles), $[\mathrm{Zn}] /[\mathrm{Ca}]$ (triangles) and (b) Cu: $[\mathrm{Cu}] /[\mathrm{Fe}]$ (squares), [Cu]/[Al] (diamonds), [Cu]/[Mg] (circles), [Cu]/[Ca] (triangles) in pregnant leach solution as function of $\mathrm{pH}$.

\subsection{Effect of MSG Concentration}

The effects of MSG concentration to metal recovery and $\mathrm{Zn}$ and $\mathrm{Cu}$ selectivity over other elements were studied between $0.1 \mathrm{M}$ and $2 \mathrm{M}$, with constant variables $\mathrm{pH}$ 9, pulp density $50 \mathrm{~g} / \mathrm{L}$ and $12 \mathrm{~h}$ leaching time at room temperature. The results in Figure 6 show that MSG concentration has positive effects on metal recovery. Based on modeling using Visual Minteq (Supplementary file: Figure S3), the minimum MSG concentration to completely solubilize $\mathrm{Zn}$ is $0.7 \mathrm{M}$, and at lower MSG concentration, $\mathrm{Zn}$ speciation is dominated by hydroxide precipitate. In the case of $\mathrm{Cu}$, the model shows that MSG concentration has little effect on speciation, which contradicts the results in Figure 6. This is probably due to competition with $\mathrm{Zn}$, which has a 40 times larger concentration. The leaching process at higher MSG concentration increased the recovery of other elements, e.g., Fe, due to increasing soluble species $\left(\mathrm{FeGlu}^{+}\right.$complex) (Supplementary file: Figure S3). The results in Figure 6 show the optimum recovery of $\mathrm{Zn}$ and $\mathrm{Cu}$ are attained at 1.2 and $0.7 \mathrm{M}$, respectively, which at higher MSG concentration did not significantly increase the recovery of both metals. At higher MSG concentration, the recovery of other metals, especially Mg and Ca became substantial, decreasing the selectivity (Figure 7). The optimum MSG concentration based on data in Figure 6 is well supported by results in Figure 7.
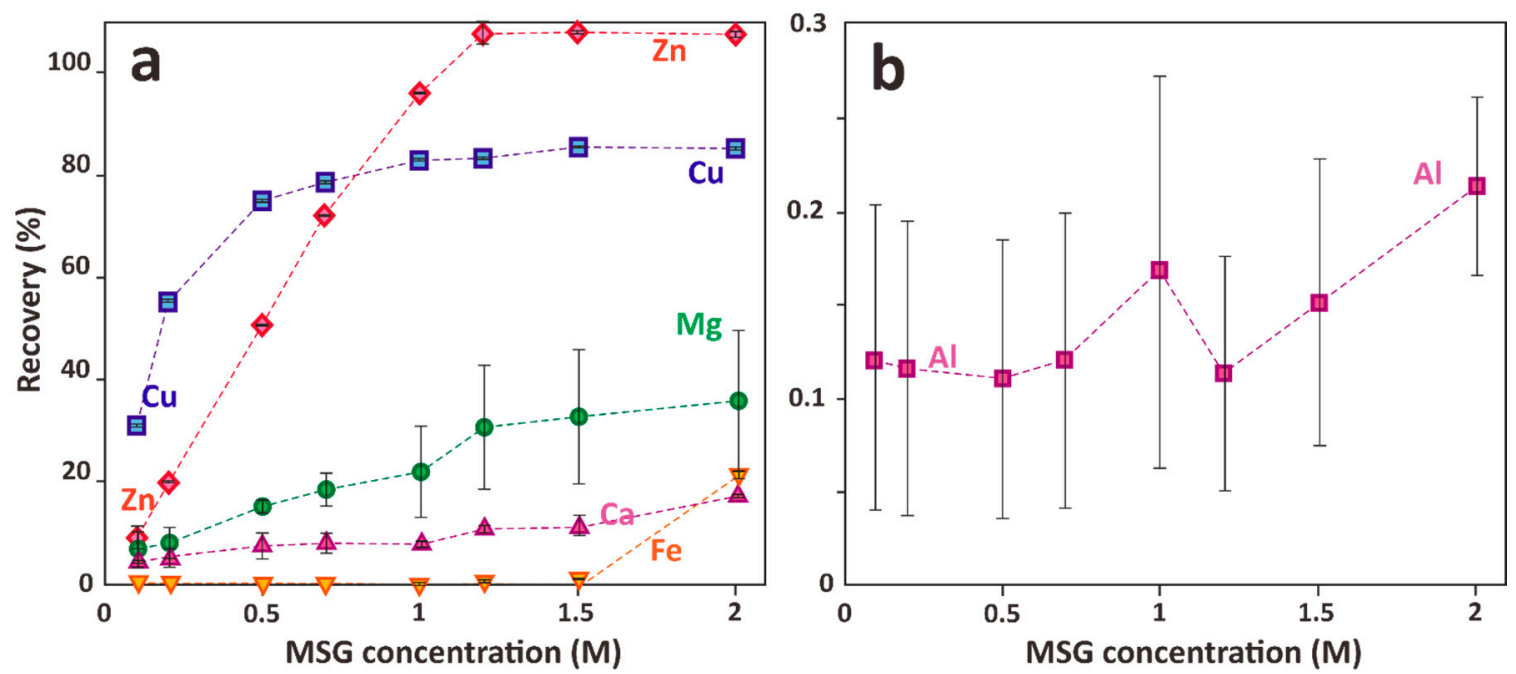

Figure 6. The recovery of (a) $\mathrm{Zn}, \mathrm{Cu}, \mathrm{Mg}$, $\mathrm{Ca}$ and $\mathrm{Fe}$ and (b) $\mathrm{Al}$ as function of MSG concentration. 


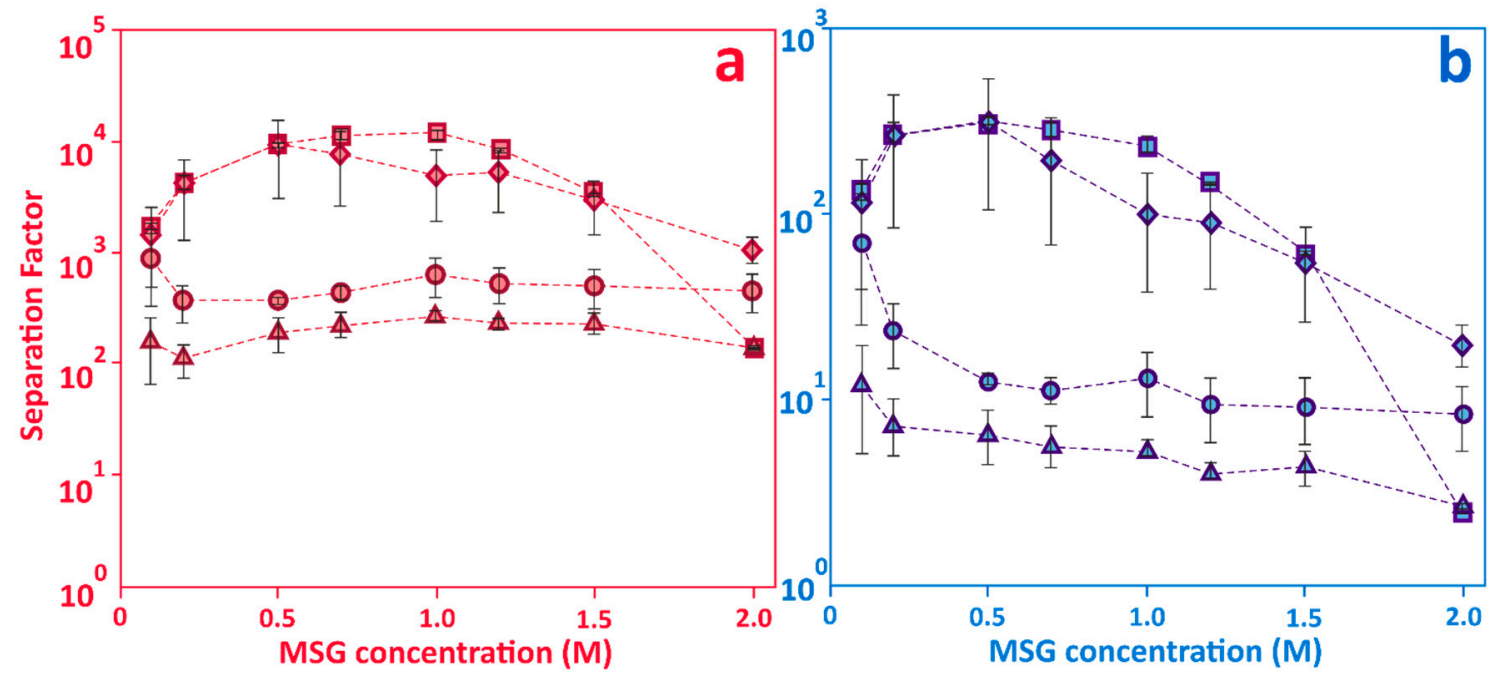

Figure 7. Separation factor of (a) Zn: [Zn]/[Fe] (squares), [Zn]/[Al] (diamonds), [Zn]/[Mg] (circles), $[\mathrm{Zn}] /[\mathrm{Ca}]$ (triangles) and (b) Cu: [Cu]/[Fe] (squares), [Cu]/[Al] (diamonds), [Cu]/[Mg] (circles), [Cu]/[Ca] (triangles) in pregnant leach solution as function of MSG concentration.

\subsection{Effect of Pulp Density}

To evaluate the effect of pulp density (ratio between lixiviant and EAF dust) on the recovery and selectivity, leaching was carried out at constant variables pH 9, MSG concentration $1 \mathrm{M}, 12 \mathrm{~h}$ leach at room temperature, while pulp density was varied between 33 and $200 \mathrm{~g} / \mathrm{L}$. The results in Figure 8 show the recovery decreased as pulp density increased. Maximum pulp density to obtain optimum recovery of $\mathrm{Zn}$ and $\mathrm{Cu}$ were 50 and $100 \mathrm{~g} / \mathrm{L}$, respectively. In the case of $\mathrm{Mg}$ and $\mathrm{Ca}$ the optimum pulp density was $66.67 \mathrm{~g} / \mathrm{L}$, while in the case of $\mathrm{Fe}$ and $\mathrm{Al}$, the recovery was very low (less than 1 percent).

The plot of separation factor value as a function of pulp density (Figure 9) reveals that pulp density has a negative effect on the separation factor. This was probably caused by the increase of solubility of elements especially $\mathrm{Mg}, \mathrm{Ca}, \mathrm{Fe}$ and $\mathrm{Al}$ at larger volumes in alkaline conditions. This also indicates the leaching of EAF dust using MSG as lixiviant in alkaline conditions should be performed using continuous methods, e.g., column leaching or heap leaching instead of a batch method, since in the continuous method the volume could be minimized to optimize the selectivity.
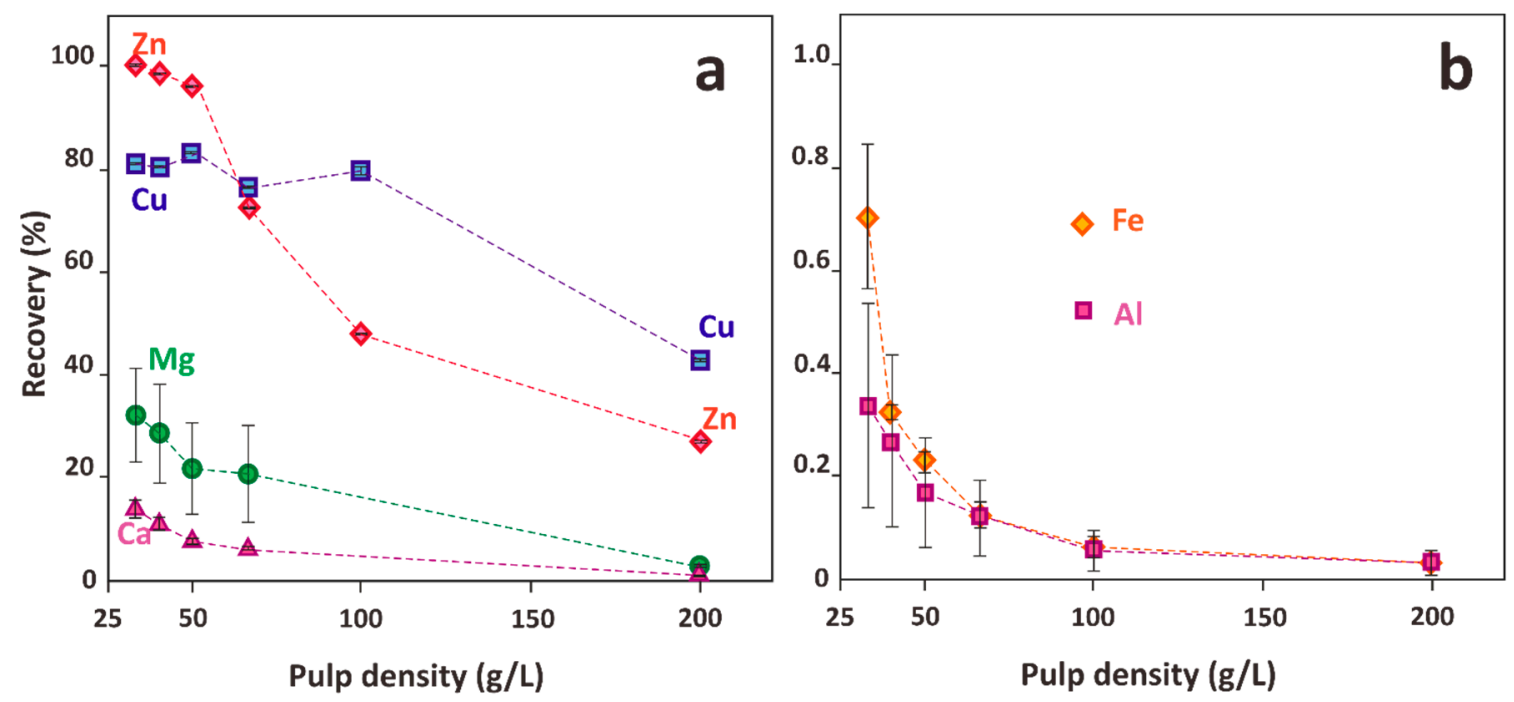

Figure 8. The recovery of (a) $\mathrm{Zn}, \mathrm{Cu}, \mathrm{Mg}$ and $\mathrm{Ca}$ and (b) Fe and $\mathrm{Al}$ as function of pulp density. 

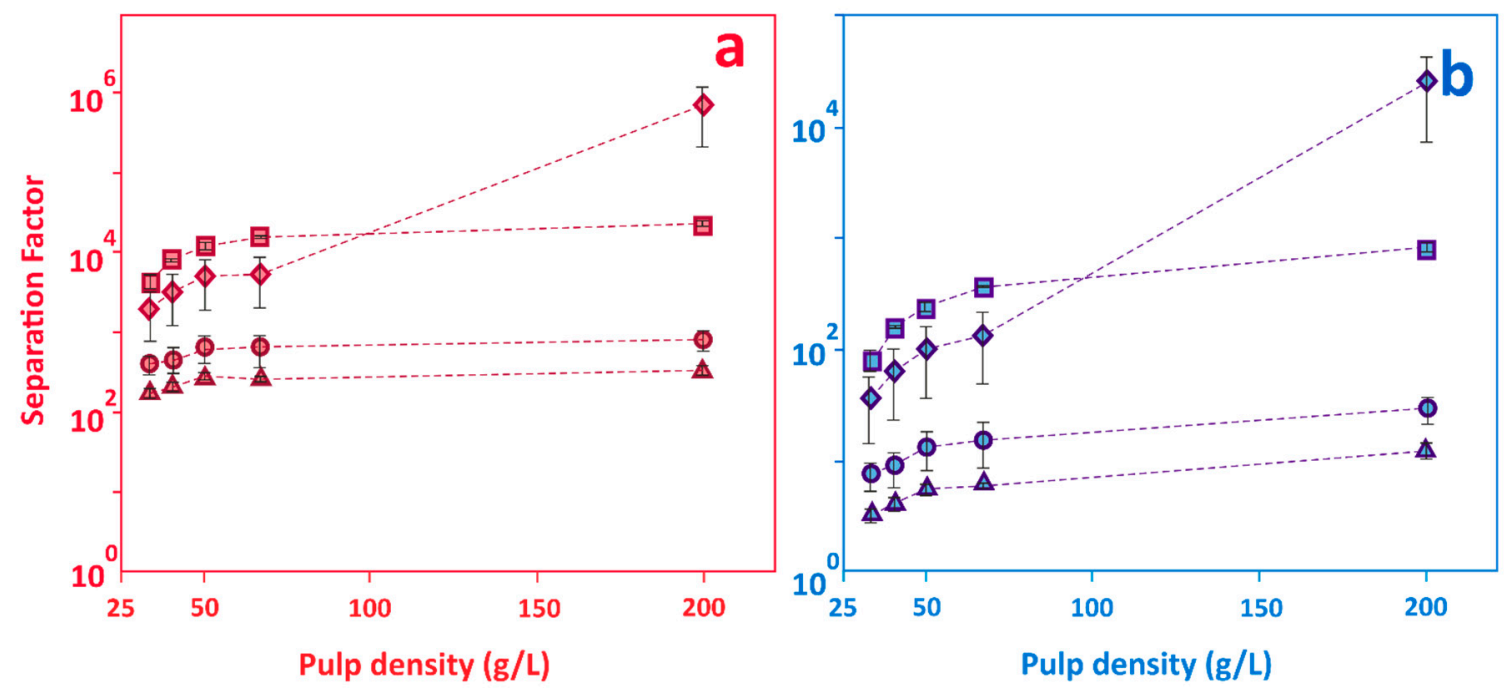

Figure 9. Separation factor of (a) Zn: [Zn]/[Fe] (squares), [Zn]/[Al] (diamonds), [Zn]/[Mg] (circles), $[\mathrm{Zn}] /[\mathrm{Ca}]$ (triangles) and (b) $\mathrm{Cu}:[\mathrm{Cu}] /[\mathrm{Fe}]$ (squares), [Cu]/[Al] (diamonds), [Cu]/[Mg] (circles), [Cu]/[Ca] (triangles) in pregnant leach solution as function of pulp density.

\subsection{Kinetic Studies (Effect of Leaching Time and Temperature)}

Kinetic studies were carried out at a time range up to $12 \mathrm{~h}$ at three different temperatures $(30,55$ and $80^{\circ} \mathrm{C}$ ), with constant variables $\mathrm{pH} 9$, MSG concentration $1 \mathrm{M}$ and pulp density $50 \mathrm{~g} / \mathrm{L}$. The results in Figure 10 show that maximum leaching efficiency was attained within $120 \mathrm{~min}$ for $\mathrm{Zn}$ and $4 \mathrm{~h}$ for $\mathrm{Cu}$ at $30^{\circ} \mathrm{C}$. At higher leaching temperature, recovery reached saturation in a shorter period. Figure $10 \mathrm{~b}$ shows the recovery of $\mathrm{Cu}$ is delayed about $1 \mathrm{~h}$. Based on Eh monitoring, in the early stage of leaching the aqueous phase was reductive, which inhibited the oxidation and complexation of $\mathrm{Cu}$ by lixiviant. As leaching progressed, the aqueous phase became oxidative, favoring the oxidation and complexation of $\mathrm{Cu}$.

To describe the kinetic process of leaching, three kinetic models were tested to model experimental data: shrinking core model (chemical reaction control), shrinking particle model (film diffusion) and interface transfer and diffusion by Dickinson and Heal (1999) [36]. The fitting results $\left(R^{2}\right.$, coefficient of correlation) of each model are listed in Table 5.
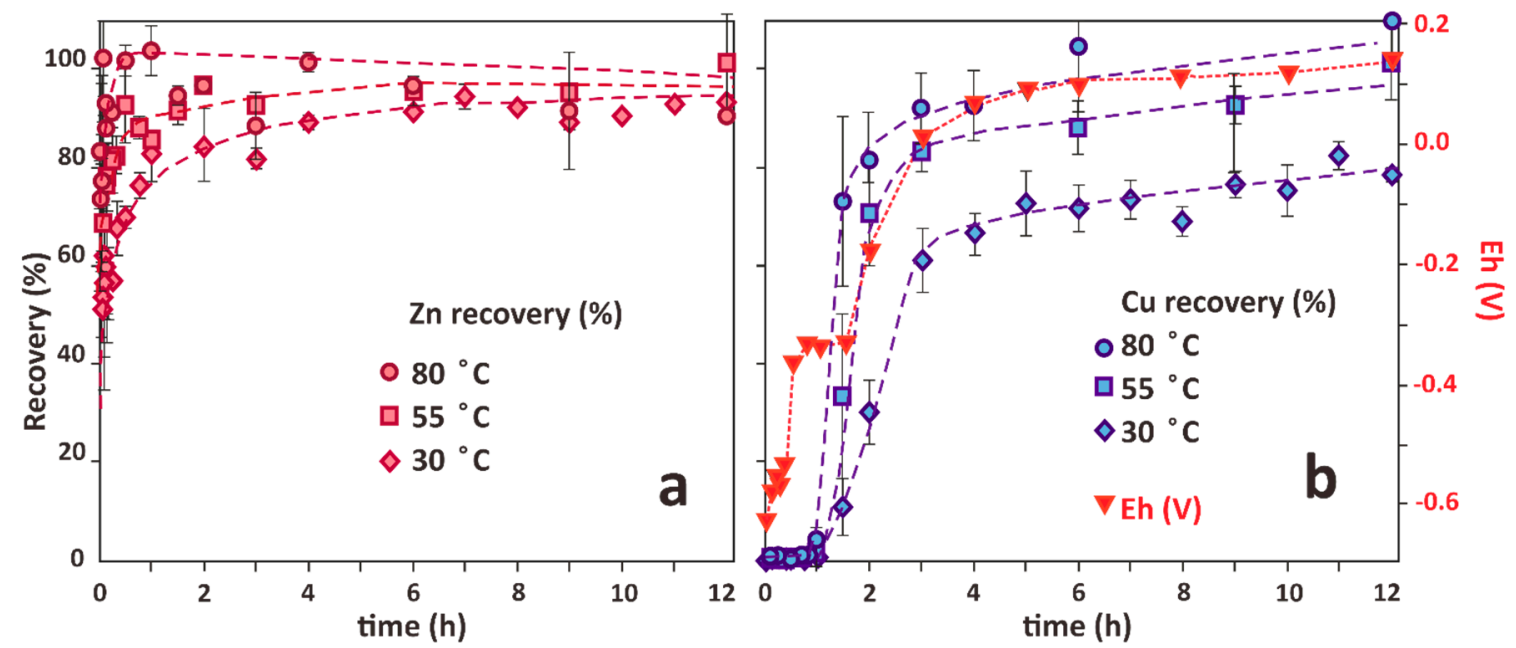

Figure 10. The effect of leaching time and temperature on recovery of (a) $\mathrm{Zn}$ and (b) $\mathrm{Cu}$. In b, the change of Eh in aqueous phase during leaching was obtained at $30{ }^{\circ} \mathrm{C}$ (single measurement). 
Table 5. Correlation coefficient for experimental data fitting using three kinetic models (SCM, shrinking core model; SPM, shrinking particle model).

\begin{tabular}{|c|c|c|c|c|c|}
\hline \multirow{2}{*}{ Element } & \multirow{2}{*}{ Model } & \multirow{2}{*}{ Equation } & \multicolumn{3}{|c|}{ Coefficient of Correlation, $R^{2}$} \\
\hline & & & $30^{\circ} \mathrm{C}$ & $55^{\circ} \mathrm{C}$ & $80^{\circ} \mathrm{C}$ \\
\hline \multirow{3}{*}{$\mathrm{Zn}$} & SCM (chemical reaction control) & $k t=1-(1-R)^{1 / 3}$ & 0.768 & 0.715 & 0.710 \\
\hline & SPM (film diffusion) & $k t=1-(1-R)^{2 / 3}$ & 0.717 & 0.635 & 0.622 \\
\hline & Interface transfer and diffusion & $k t=1 / 3 \ln (1-x)-\left[1-(1-x)^{-1 / 3}\right]$ & 0.886 & 0.916 & 0.895 \\
\hline \multirow{3}{*}{$\mathrm{Cu}$} & SCM (chemical reaction control) & $k t=1-(1-R)^{1 / 3}$ & 0.880 & 0.847 & 0.912 \\
\hline & SPM (film diffusion) & $k t=1-(1-R)^{2 / 3}$ & 0.860 & 0.802 & 0.885 \\
\hline & Interface transfer and diffusion & $k t=1 / 3 \ln (1-x)-[1-(1-x)-1 / 3]$ & 0.930 & 0.969 & 0.931 \\
\hline
\end{tabular}

$k$, apparent rate constant $\left(\mathrm{min}^{-1}\right) ; t$, time $(\mathrm{min}) ; R$, metal recovery.

Based on the coefficient of the correlation value in Table 5, the interface transfer and diffusion model is the best model to describe the experimental data. Although the shrinking core model and shrinking particle model are more popular models to explain kinetic data, both models are generally based on the assumption of constant lixiviant concentration during leaching [37]. In the leaching process, the concentration of glutamate would decrease due to complex formation. In this study, the model developed by Dickinson and Heal (1999) [36] was adequately applied to analyze the dissolution of $\mathrm{Zn}$ and $\mathrm{Cu}$ in EAF dust using glutamate.

The value of the apparent rate constant $(k)$ obtained for each temperature using the interface transfer and diffusion model (Table 6$)$ was used to determine the activation energy $\left(E_{a}, \mathrm{~kJ} / \mathrm{mol}\right)$ using the Arrhenius Equation (3), where $A, T$, and $R$ are the frequency factor, temperature, and gas constant, respectively. Relatively low energy activation for both $\mathrm{Zn}$ and $\mathrm{Cu}$ indicates that the effect of temperature on the leaching process is minor.

$$
k=A e^{-\frac{E_{a}}{R T}} \text { or } \ln k=\ln A-\frac{E_{a}}{R T}
$$

Table 6. Apparent rate constant $(k)$ attained from fitting of experimental data using interface transfer and diffusion model, which was used to obtain the activation energy $\left(E_{a}\right)$ using linear regression, including the coefficient of correlation $\left(R^{2}\right)$.

\begin{tabular}{cccccc}
\hline \multirow{2}{*}{ Element } & \multicolumn{3}{c}{$k\left(\mathbf{m i n}^{-\mathbf{1}}\right)$} & \multirow{2}{*}{$\boldsymbol{E}_{\boldsymbol{a}} \mathbf{( \mathbf { k J } / \mathbf { m o l } )}$} & \multirow{2}{*}{$\boldsymbol{R}^{\mathbf{2}}$} \\
\cline { 2 - 4 } & $\mathbf{3 0}{ }^{\circ} \mathbf{C}$ & $\mathbf{5 5}{ }^{\circ} \mathbf{C}$ & $\mathbf{8 0}{ }^{\circ} \mathbf{C}$ & & \\
\hline $\mathrm{Zn}$ & $7.3 \times 10^{-4}$ & $1.9 \times 10^{-3}$ & $5.4 \times 10^{-3}$ & 35.5 & 0.995 \\
\hline $\mathrm{Cu}$ & $3.0 \times 10^{-4}$ & $1.0 \times 10^{-3}$ & $2.2 \times 10^{-3}$ & 35.6 & 0.994 \\
\hline
\end{tabular}

\subsection{Monosodium Glutamate Recovery}

Due to the significant amount of MSG used in leaching and to sustain the leaching scheme, the regeneration of glutamate is required. Glutamate could be recovered from the pregnant leach solution as precipitate by acidifying the solution to the $\mathrm{pH}$ between 2-4.5. In this $\mathrm{pH}$ range glutamate is precipitated as neutral species glutamic acid, $\mathrm{H}_{2} \mathrm{Glu}$ (Supplementary file: Figure $\mathrm{S} 4$ ). The addition of more acid ( $\mathrm{pH}$ less than 1) caused the formation of soluble cationic species $\mathrm{H}_{3} \mathrm{Glu}^{+}$. The experiment performed to recover glutamate from the pregnant leach solution showed that the optimum $\mathrm{pH}$ was 3 , which in this $\mathrm{pH}$ more than $90 \%$ of the glutamate was recovered as glutamic acid (Figure 11). The recovery efficiency of glutamate was determined gravimetrically. 


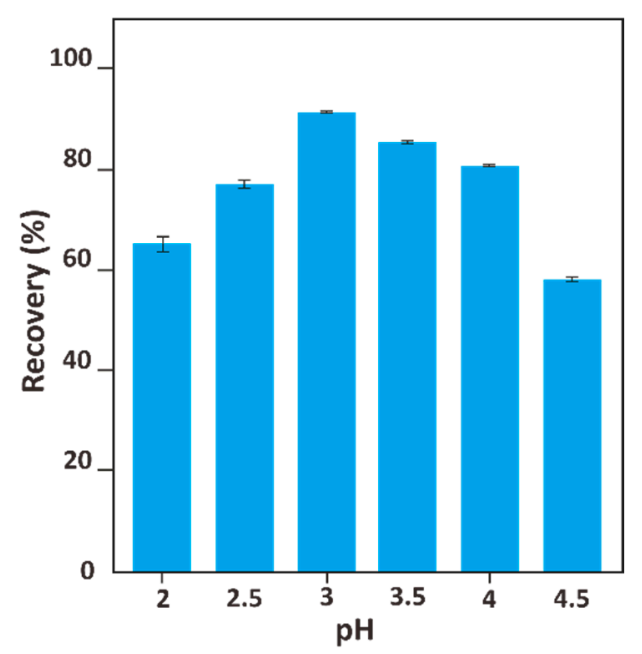

Figure 11. Monosodium glutamate (MSG) recovery efficiency as function of $\mathrm{pH}$.

\section{Conclusions}

Monosodium glutamate effectively and selectively recovered $\mathrm{Zn}$ and $\mathrm{Cu}$ from EAF dust, based on batch leaching studies according to leaching efficiency and separation factor values. The optimum conditions for the leaching scheme are $\mathrm{pH}$ 9, lixiviant concentration $1 \mathrm{M}$ and pulp density $50 \mathrm{~g} / \mathrm{L}$. Studies on the effect of pulp density on the metal recovery and separation factor showed that pulp density correlated negatively to the metal recovery and positively to the separation factor of $\mathrm{Zn}$ and $\mathrm{Cu}$ to the other elements. This indicates the leaching is better performed using a continuous method, considering the selective recovery of $\mathrm{Zn}$ and $\mathrm{Cu}$ from other elements. Kinetic studies showed the leaching efficiency reached a saturation value in less than 2 and $4 \mathrm{~h}$ for $\mathrm{Zn}$ and $\mathrm{Cu}$, respectively. The activation energy obtained from the experimental data modeling revealed the effect of temperature on the leaching process was minor. Further the use of MSG as lixiviant offers a sustainable leaching scheme since MSG is recoverable from the pregnant leach solution and reusable for the next leaching cycle.

Supplementary Materials: The following are available online at http://www.mdpi.com/2075-4701/10/5/644/s1, Figure S1: Species distribution of (a) $\mathrm{Al}$, (b) $\mathrm{Fe}$, (c) $\mathrm{Mg}$ and (d) $\mathrm{Ca}$ in glutamate- $\mathrm{H}_{2} \mathrm{O}$ system as function of $\mathrm{pH}$. Glutamate concentration $1 \mathrm{M}, \mathrm{Al}^{2+} 350 \mathrm{mM}, \mathrm{Fe}^{3+} 10 \mathrm{mM}, \mathrm{Mg}^{2+} 10 \mathrm{mM}$ and $\mathrm{Ca}^{2+} 20 \mathrm{mM}$, Table S1: AMICS Mineralogy for Zinc EAF Dust Sample, Figure S2: Identified AMICS Minerals for Zinc EAF Dust Sample, Table S2, AMICS Color Scheme, Figure S3: Species distribution of (a) $\mathrm{Zn}$ and (b) Fe in glutamate- $\mathrm{H}_{2} \mathrm{O}$ system as function of glutamate concentration at $\mathrm{pH} 9 . \mathrm{Zn}^{2+} 300 \mathrm{mM}$ and $\mathrm{Fe}^{3+} 10 \mathrm{mM}$, Figure S4: Species distribution of glutamate in glutamate- $\mathrm{H}_{2} \mathrm{O}$ system as function of $\mathrm{pH}$. Glutamate concentration $1 \mathrm{M}$.

Author Contributions: Conceptualization, E.P.; data curation, E.P.; formal analysis, E.P. and C.A.; funding acquisition, E.P. and C.A.; investigation, E.P. and C.A.; methodology, E.P.; project administration, F.R.M., E.P.; resources, E.P., C.A., F.N., M.A.M., A.S.H., F.R.M. and F.B.; validation, E.P.; visualization, M.A.M. and F.B.; writing-original draft, E.P.; writing-review \& editing, E.P. and C.A. All authors have read and agreed to the published version of the manuscript.

Funding: This research was funded and supported by Indonesian Institute of Sciences FY 2019, Fulbright Program through Visiting Scholar Scheme 2019-2020, Indonesian Ministry of Research and Technology Insinas Program FY 2020, PRN (National Priority Research) of Indonesia FY 2020.

Acknowledgments: We would like to express our gratitude to the two reviewers for improving this manuscript.

Conflicts of Interest: The authors declare no conflict of interest.

\section{References}

1. Ejtemaei, M.; Gharabaghi, M.; Irannajad, M. A review of zinc oxide mineral beneficiation using flotation method. Adv. Colloid Interface Sci. 2014, 206, 68-78. [CrossRef] [PubMed]

2. Martins, F.M.; dos Neto, J.M.R.; da Cunha, C.J. Mineral phases of weathered and recent electric arc furnace dust. J. Hazard. Mater. 2008, 154, 417-425. [CrossRef] 
3. Suetens, T.; Klaasen, B.; Van Acker, K.; Blanpain, B. Comparison of electric arc furnace dust treatment technologies using exergy efficiency. J. Clean. Prod. 2014, 65, 152-167. [CrossRef]

4. Youcai, Z.; Stanforth, R. Extraction of zinc from zinc ferrites by fusion with caustic soda. Miner. Eng. 2000, 13, 1417-1421. [CrossRef]

5. Wang, C.; Guo, Y.F.; Wang, S.; Chen, F.; Tan, Y.J.; Zheng, F.Q.; Yang, L.Z. Characteristics of the reduction behavior of zinc ferrite and ammonia leaching after roasting. Int. J. Miner. Metall. Mater. 2020, 13, 1417-1421. [CrossRef]

6. Lupi, C.; Pilone, D. Effectiveness of saponified D2EHPA in Zn(II) selective extraction from concentrated sulphuric solutions. Miner. Eng. 2020, 150, 106278. [CrossRef]

7. Zhu, Z.; Cheng, C.Y. A Study on zinc recovery from leach solutions using ionquest 801 and its mixture with D2EHPA. Miner. Eng. 2012, 39, 117-123. [CrossRef]

8. Zhou, K.; Wu, Y.; Zhang, X.; Peng, C.; Cheng, Y.; Chen, W. Removal of Zn(II) from manganese-zinc chloride waste liquor using ion-exchange with D201 resin. Hydrometallurgy 2019, 190, 105171. [CrossRef]

9. Rudnik, E. Recovery of zinc from zinc ash by leaching in sulphuric acid and electrowinning. Hydrometallurgy 2019, 188, 256-263. [CrossRef]

10. Youcai, Z.; Chenglong, Z.; Youcai, Z.; Chenglong, Z. Electrowinning of Zinc and Lead from Alkaline Solutions. In Pollution Control and Resource Reuse for Alkaline Hydrometallurgy of Amphoteric Metal Hazardous Wastes; Springer: Berlin/Heidelberg, Germany, 2017. [CrossRef]

11. Halli, P.; Hamuyuni, J.; Revitzer, H.; Lundström, M. Selection of leaching media for metal dissolution from electric arc furnace dust. J. Clean. Prod. 2017, 164, 265-276. [CrossRef]

12. Kukurugya, F.; Vindt, T.; Havlík, T. Behavior of Zinc, Iron and Calcium from Electric Arc Furnace (EAF) dust in hydrometallurgical processing in sulfuric acid solutions: Thermodynamic and kinetic aspects. Hydrometallurgy 2015, 154, 20-32. [CrossRef]

13. Montenegro, V.; Agatzini-Leonardou, S.; Oustadakis, P.; Tsakiridis, P. Hydrometallurgical treatment of EAF dust by direct sulphuric acid leaching at atmospheric pressure. Waste Biomass Valoriz. 2016, 7, 1531-1548. [CrossRef]

14. Rudnik, E. Investigation of industrial waste materials for hydrometallurgical recovery of Zinc. Miner. Eng. 2019, 139. [CrossRef]

15. Teo, Y.Y.; Lee, H.S.; Low, Y.C.; Choong, S.W.; Low, K.O. Hydrometallurgical extraction of Zinc and Iron from Electric Arc Furnace Dust (EAFD) Using Hydrochloric Acid. J. Phys. Sci. 2018, 29, 49-54. [CrossRef]

16. Kusumaningrum, R.; Fitroturokhmah, A.; Sinaga, G.S.T.; Wismogroho, A.S.; Widayatno, W.B.; Diguna, L.J.; Amal, M.I. Study: leaching of zinc dust from electric arc furnace waste using oxalic acid. In IOP Conference Series: Materials Science and Engineering; IOP Publishing: Bristol, UK, 2019. [CrossRef]

17. Halli, P.; Hamuyuni, J.; Leikola, M.; Lundström, M. Developing a sustainable solution for recycling electric arc furnace dust via organic acid leaching. Miner. Eng. 2018, 124, 1-9. [CrossRef]

18. Dutra, A.J.B.; Paiva, P.R.P.; Tavares, L.M. Alkaline leaching of zinc from electric arc furnace steel dust. Miner. Eng. 2006, 19, 478-485. [CrossRef]

19. Palimakaa, P.; Pietrzyk, S.; Stępień, M.; Ciećko, K.; Nejman, I. Zinc Recovery from steelmaking dust by hydrometallurgical methods. Metals (Basel) 2018, 8, 547. [CrossRef]

20. Zhang, D.; Ling, H.; Yang, T.; Liu, W.; Chen, L. Selective Leaching of Zinc from Electric Arc Furnace dust by a hydrothermal reduction method in a sodium hydroxide system. J. Clean. Prod. 2019, 224, 536-544. [CrossRef]

21. Al-Makhadmeh, L.A.; Batiha, M.A.; Al-Harahsheh, M.S.; Altarawneh, I.S.; Rawadieh, S.E. The effectiveness of Zn leaching from EAFD using caustic soda. Water. Air. Soil Pollut. 2018, 229, 33. [CrossRef]

22. Ma, A.; Zheng, X.; Shi, S.; He, H.; Rao, Y.; Luo, G.; Lu, F. Study on recovery of Zinc from metallurgical solid waste residue by ammoniacal leaching. In Minerals, Metals and Materials Series; Springer: Berlin/Heidelberg Germany, 2019. [CrossRef]

23. Zhang, D.; Zhang, X.; Yang, T.; Rao, S.; Hu, W.; Liu, W.; Chen, L. Selective leaching of Zinc from blast furnace dust with mono-ligand and mixed-ligand complex leaching systems. Hydrometallurgy 2017, 169, 219-228. [CrossRef]

24. Yang, T.; Rao, S.; Zhang, D.; Wen, J.; Liu, W.; Chen, L.; Zhang, X. Leaching of low grade zinc oxide ores in nitrilotriacetic acid solutions. Hydrometallurgy 2016, 161, 107-111. [CrossRef] 
25. Herrero, D.; Arias, P.L.; Güemez, B.; Barrio, V.L.; Cambra, J.F.; Requies, J. Hydrometallurgical process development for the production of a zinc sulphate liquor suitable for electrowinning. Miner. Eng. 2010, 23, 511-517. [CrossRef]

26. Eksteen, J.J.; Oraby, E.A.; Tanda, B.C. A conceptual process for copper extraction from chalcopyrite in alkaline glycinate solutions. Miner. Eng. 2017, 108, 53-66. [CrossRef]

27. Oraby, E.A.; Eksteen, J.J.; Karrech, A.; Attar, M. Gold extraction from paleochannel ores using an aerated alkaline glycine lixiviant for consideration in heap and in-situ leaching applications. Miner. Eng. 2019, 138, 112-118. [CrossRef]

28. Prasetyo, E. Monosodium Glutamate For Simple Photometric Iron Analysis. In IOP Conference Series: Materials Science and Engineering; IOP Publishing: Bristol, UK, 2018. [CrossRef]

29. Prasetyo, E. Simple method of copper analysis using monosodium glutamate and its application in ore analysis. Mineralogia 2012, 43, 137-146. [CrossRef]

30. Prasetyo, E.; Bahfie, F.; Al Muttaqii, M.; Handoko, A.S.; Nurjaman, F. Zinc extraction from electric arc furnace dust using amino acid leaching. In AIP Conference Proceeding; AIP Publishing: College Park, MA, USA, 2020.

31. Gustafsson, J.P. Visual MINTEQ Ver. 3.1. Available online: https://vminteq.lwr.kth.se/visual-minteq-ver-3-1/ (accessed on 4 August 2019).

32. Leonard, M. Vogel's textbook of quantitative chemical analysis. Endeavour 1990, 14, 100. [CrossRef]

33. Anderegg, G. Critical survey of stability constants of EDTA complexes. In Critical Survey of Stability Constants of EDTA Complexes; Pergamon: Oxford, UK, 1977. [CrossRef]

34. Anderegg, G. Critical survey of stability constants of Nta complexes. Pure Appl. Chem. 2013, 54, $2693-2758$. [CrossRef]

35. Kiss, T.; Sovago, I.; Gergely, A. Critical survey of stability constants of complexes of glycine. Pure Appl. Chem. 2007, 63, 597-638. [CrossRef]

36. Dickinson, C.F.; Heal, G.R. Solid-liquid diffusion controlled rate equations. Thermochim. Acta 1999, 340, 89-103. [CrossRef]

37. Rao, S.; Yang, T.; Zhang, D.; Liu, W.F.; Chen, L.; Hao, Z.; Xiao, Q.; Wen, J.F. Leaching of low grade zinc oxide ores in nh4cl-nh3 solutions with nitrilotriacetic acid as complexing agents. Hydrometallurgy 2015, 158, 101-106. [CrossRef]

(C) 2020 by the authors. Licensee MDPI, Basel, Switzerland. This article is an open access article distributed under the terms and conditions of the Creative Commons Attribution (CC BY) license (http://creativecommons.org/licenses/by/4.0/). 